\title{
Comparison of Rugae Pattern between Dentulous and Edentulous Population of Rajasthan State
}

\section{Garima Bhatt*}

Darshan Dental College and Hospital, Udaipur, Rajasthan, India

\begin{abstract}
Context: Palatal rugae are irregular, transverse palatine folds of the mucous membrane located on the anterior third on the palate. The study of palatal rugae is known as palatal rugoscopy. It has been shown that palatal rugae are unique to every person so they are useful in forensic identification.
\end{abstract}

Aim: To examine the palatal rugae pattern in dentulous and edentulous individuals.

Settings and design: The total samples of 100 participants were taken divided in two groups consisting of 50 dentulous and 50 edentulous participants.

Methods and material: The Number, length and qualitative characteristics of rugae were recorded on maxillary casts which were delineated using sharp graphite pencil based on the classification proposed by Thomas and Kotze.

Statistical analysis used: Data obtained using these criteria and prepared for statistical analysis using student t-test.

Results: Distribution of rugae and rugae patterns were not symmetrical in both the groups. Total number of rugae were more in dentulous group than edentulous group and the complex rugae patterns were also seen more in dentulous group while edentulous group consisting of more simple form of rugae patterns.

Conclusions: There were significant differences in the size and shape of the rugae pattern between dentulous and edentulous population.

Keywords: Age groups; Casts; Dentistry; Edentulous; Forensic; Identification

\section{Introduction}

Forensic Odontology is a speciality in dentistry which occupies a prime slot within the total range of methods applied to medico-legal credentials [1]. Forensic odontology can be defined as a branch of dentistry which deals with the appropriate handling and examination of dental evidence with the proper evaluation and presentation of dental findings in the interest of justice [2].

Human identification is a mainstay of civilization, whether in living or dead, and the identification of unknown individual has always been of paramount importance to our society [3]. In forensic dentistry, the oral cavity plays a very important role because of the unique anatomy of the teeth [4]. In certain situations, if teeth are lost due to any reason, the most common of which is trauma, then the use of human palatal rugae has been suggested as an alternative method for identification and the name given to the study of palatal rugae is known as palatoscopy or palatal rugoscopy $[4,5]$. The use of palatal rugae was suggested as one of the method of identification in 1889 by Harrison Allen [6]. Transverse palatine folds or palatal rugae are asymmetrical and irregular elevations of the mucosa in the anterior third of the palate, made from the lateral membrane of the incisive papillae, arranged in a transverse direction from the palatine raphe located in the mid sagittal plane and supplied by the greater palatine and nasopalatine branches [3,7-9]. The purpose of palatal rugae is to facilitate food transportation through the oral cavity, prevent loss of food from the mouth and participate in chewing process [10]. Due to the presence of gustatory and tactile receptors, they contribute to the perception of taste, texture of food qualities and tongue position during speech [10]. These important rugae features encouraged many researchers to reproduce the individual palatal rugae on the dentures' palatal surfaces $[11,12]$.
In prosthodontics, rugae area plays an effective role; it is a secondary bearing area that resists anterior displacement of the denture, it is considered as a part of the primary denture supporting area because it does not affected by resorption sometimes rugae area is covered to provide indirect retention for free extended denture base and there were efforts to use palatal rugae as a guide in positioning the artificial maxillary anterior teeth $[12,13]$.

Once formed in third month in uterus, palatal rugae do not undergo any changes except in length due to normal growth and remain stable throughout an entire person's life [12]. However, some events can contribute to changes in palatal rugae including extreme finger sucking in infancy and persistent pressure with orthodontic treatment or dentures [10,14-16]. The presence and absence of teeth either due to extraction or as a result of edentulism is the criteria which led us to undertake the study with the aim to compare rugae pattern between dentulous and edentulous population.

\section{Subjects and Methods}

The study consisted of a total number of 100 individuals of dentulous

*Corresponding author: Dr. Garima bhatt, Darshan Dental College and Hospital, Oral and Maxillofacial Pathology, Loyara, Ranakpur Road, Udaipur Rajasthan 313001, India, Tel: 919461834011; E-mail: dr_gbhatt8@yahoo.com

Received November 02, 2014; Accepted November 13, 2014; Published November 20, 2014

Citation: Bhatt G (2015) Comparison of Rugae Pattern between Dentulous and Edentulous Population of Rajasthan State. J Forensic Res 5: 254. doi:10.4172/21577145.1000254

Copyright: @ 2015 Bhatt $\mathrm{G}$. This is an open-access article distributed under the terms of the Creative Commons Attribution License, which permits unrestricted use, distribution, and reproduction in any medium, provided the original author and source are credited. 
Citation: Bhatt G (2015) Comparison of Rugae Pattern between Dentulous and Edentulous Population of Rajasthan State. J Forensic Res 5: 254. doi:10.4172/2157-7145.1000254

Page 2 of 3

and edentulous groups, who were selected among the patients visiting the hospital. Informed consent was obtained from all the individuals. The procedure performed was as per the criteria of institutional ethical committee and the Helkinsen declaration of 1972.

The young individuals of dentulous group having age range 1530 years while edentulous group having age range 50-75 years were included in the present study. Age range of 15-30 years represents the age of growth completion and certainly after this age many changes occur in dentition due to the aging process, extensive restorative dental treatment and teeth loss.

\section{Exclusion Criteria}

Subjects with congenital anomalies/malformations, previous orthognathic surgery, allergic to impression material, bony and soft tissue protuberances, active lesions, deformity or scars and trauma of the palate.

All the initial impressions, which were taken from the patients, were made from alginate impression materials and the casts were made from hard dental stone. After obtaining the study models, the rugae were delineated using a sharp graphite pencil under adequate light and magnification and recorded according to the classification given by Thomas and Kotze [17].

The collected data were further analysed using paired t-test to detect any significant differences. Statistical analysis was performed using SPSS software version 16.

\section{Results}

This study was conducted at the Department of Oral Pathology and Microbiology, Darshan Dental College and Hospital, Udaipur. A total of 100 maxillary dental casts obtained from 50 dentulous and 50 edentulous individuals, were examined for the palatal rugae patterns (Table 1), using the classification proposed by Thomas and Kotze [17] as per the number, direction, shape, length and unification patterns (Figure 1).

\section{The total number of rugae}

The total number of rugae was more in dentulous $(8.02 \pm 1.464)$ than edentulous $(6.74 \pm 1.07)$ individuals.

\section{Direction}

The incidence of forwardly directed rugae $(4.12 \pm 1.803)$ are more in dentulous population while perpendicular rugae $(3.86 \pm 1.90)$ were more in edentulous population and there is no difference in backwardly directed rugae pattern.

\section{Shape}

The incidence of curved rugae patterns $(3.46 \pm 1.606)$ are found to be more in dentulous population while straight rugae patterns $(4.22 \pm$ 1.54 ) are found to be more in edentulous population.

\section{Length}

Number of primary rugae $(7.66 \pm 1.686)$ is more in dentulous population and there is no difference in the mean of secondary rugae patterns.

\section{Unification}

The converging and diverging patterns do not show any mean difference.

\section{Discussion}

Establishing a person's identity can be a very difficult process. Fingerprints and dental means represent the most scientifically reliable methods of identification [18]. In the field of forensic odontology, rugoscopy is still in its infancy $[3,19]$. Despite the on-going problem of describing palatal rugae pattern, quantitatively and qualitatively, their uniqueness to individuals has been recognized clearly as providing a potentially reliable source of identification $[3,20]$.

In the present study, most common rugae shapes found among both the groups were straight and curved followed by wavy and circular. Regarding the direction, forwardly directed rugae were more in dentulous population while perpendicular rugae were more in edentulous population and there was no difference in backwardly directed rugae pattern. This finding was in contrary with the results of Jawad IA [12] in Iraq population and of Kapali et al. [14] in Australian individuals. This difference in shapes could be because of different environmental and genetic expression.

In the present study, regarding different patterns, circular and wavy forms were more frequent in dentulous group than in edentulous; whereas curved and straight shapes were most prominent in the edentulous group. This finding goes in accordance with Jawad IA [12].

A study carried out by Ohtani et al. [21] to explore the availability and the limitations of using the palatal rugae pattern in forensic practice for personal identification, stated that in edentulous patients, features like poorly demarcated eminence of rugae and non-complex rugae pattern were mainly due to shape of edentulous palate itself and rarely due to the dentures and could lead to difficulties in finding unique points for personal identification. The continuous forces exerted by chewing and mechanical stimulation can result in much morphological degeneration in the palatal mucosa involving rugae [12]. This may be attributed to the significant changes occurring in the rugae position especially at their lateral ends which were believed to follow the direction of tooth migration; a physiological process that occurs after loss of adjacent teeth, in correlation with the bone resorption at the maxillary arch circumference $[12,15]$.

\begin{tabular}{|c|c|c|c|c|c|c|c|c|c|c|c|c|c|}
\hline \multirow[b]{2}{*}{ Study Group } & \multirow[b]{2}{*}{ Number } & \multicolumn{2}{|c|}{ Direction } & \multicolumn{5}{|c|}{ Shape } & \multicolumn{3}{|c|}{ Length } & \multicolumn{2}{|c|}{ Unification } \\
\hline & & Forward & Backward & Perpendicular & Curve & Wavy & Straight & Circular & Primary & Secondary & Fragmentary & Converging & Diverging \\
\hline $\begin{array}{c}\text { Dentulous } \\
\text { (Mean) }\end{array}$ & 8.02 & 4.12 & 1.36 & 2.54 & 3.46 & 0.68 & 3.74 & 0.06 & 7.66 & 0.18 & 0 & 0.18 & 0.44 \\
\hline SD & 1.464 & 1.803 & 1.495 & 1.619 & 1.606 & 0.957 & 1.639 & 0.314 & 1.686 & 0.560 & 0.000 & 0.438 & 0.577 \\
\hline $\begin{array}{l}\text { Edentulous } \\
\text { (Mean) }\end{array}$ & 6.74 & 1.60 & 1.30 & 3.86 & 2.26 & 0.20 & 4.22 & 0.02 & 6.68 & 0.06 & 0.00 & 0.18 & 0.58 \\
\hline SD & 1.07 & 1.48 & 1.31 & 1.90 & 1.38 & 0.49 & 1.54 & 0.14 & 1.02 & 0.31 & 0.00 & 0.44 & 0.64 \\
\hline $\mathrm{t}$ value & 4.999 & 7.630 & 0.213 & -3.745 & 4.004 & 3.150 & -1.508 & 0.822 & 3.518 & 1.322 & 0 & 0.000 & -1.147 \\
\hline$p$ value & $<0.01$ & $<0.001$ & $>0.05$ & $<0.001$ & $<0.001$ & $<0.01$ & $>0.05$ & $>0.05$ & $<0.001$ & $>0.05$ & NA & $>0.05$ & $>0.05$ \\
\hline
\end{tabular}

Table 1: The mean and standard deviation of the palatal rugae pattern in the study groups. 
Citation: Bhatt G (2015) Comparison of Rugae Pattern between Dentulous and Edentulous Population of Rajasthan State. J Forensic Res 5: 254. doi:10.4172/2157-7145.1000254

Page 3 of 3

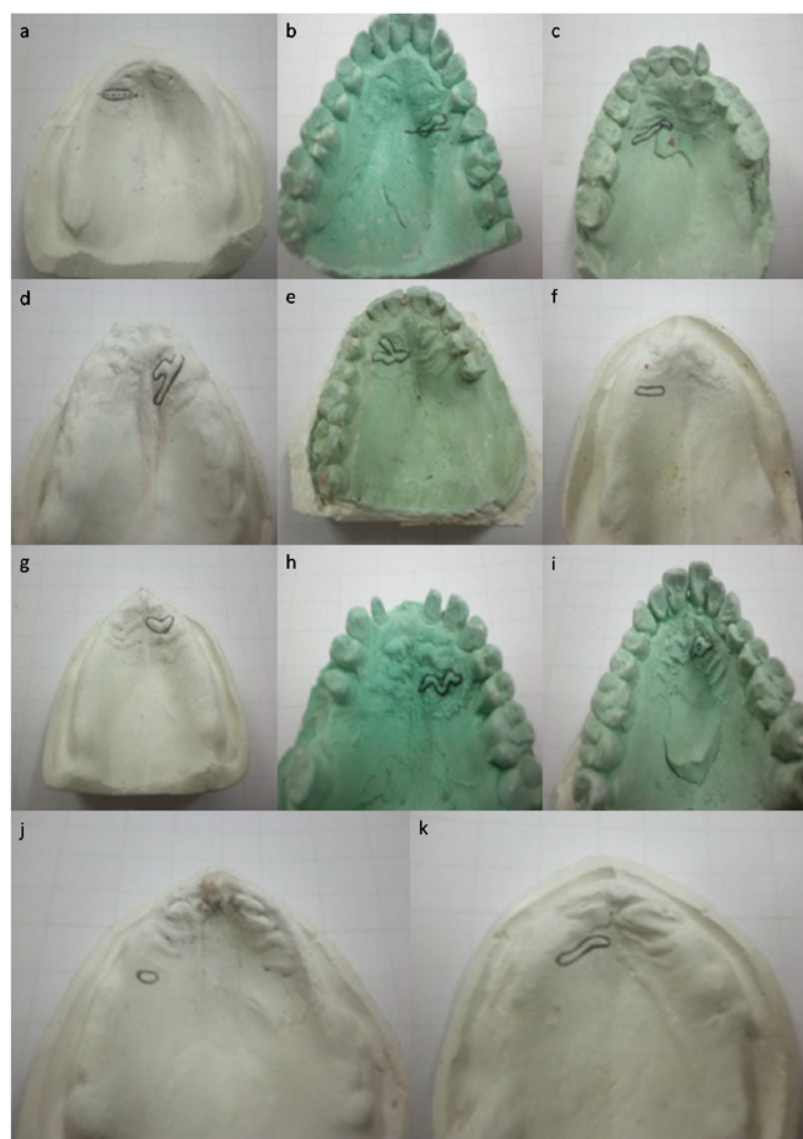

Figure 1: The photograph of the maxillary casts showing the palatal rugae as per the directions $(a-c)$, shape $(d-g)$, length $(h-j)$ and unification $(k$ and I) patterns.

The common concern about palatal rugae voiced by many researchers was the possibility of changing rugae patterns with age and other outside influences. However Bansode [4] stated that the changes occurring during extractions and tooth movement do not significantly alter the pattern of rugae. Due to these controversies regarding the changes occurring in the palatal region as a result of aging, further investigations should be carried out to check out the influence of bone resorption and denture wearing on the palatal rugae.

\section{Conclusion}

Pattern of palatal rugae changes after aging and tooth loss. The dentulous groups were showing more complexity in the rugae pattern whereas edentulous groups were showing straight and simple rugae patterns. Edentulous group possess following dominant features; reduced number, shorter lengths, lesser complexity and perplexity, more perpendicular than those in young dentate individuals.

\section{References}

1. Prasad KD, Bhagwati BT, Mittal S (2012) Role of Forensic Odontologist in Medico-Legal Investigation-An Overview. Medico-Legal Update 12: 36-41.

2. Siddique S, Panchmal GS (2011) Palatal Rugae-A tool in forensic odontology. Medico-legal Update: An International Journal 11: 51-56.

3. Shetty M, Premalatha K (2011) Study of Palatal Rugae Pattern among the Student Population in Mangalore. J Indian Acad Forensic Med 33: 112-115.
4. Bansode SC, Kulkarni MM (2009) Importance of palatal rugae in individual identification. J Forensic Dent Sci 1: 77-81.

5. Bhullar A, Kaur RP, Kamat MS (2011) Palatal Rugea-an Aid in Clinical Dentistry. J Forensic Res 2: 1-4.

6. Indira AP, Gupta M, David MP (2011) Rugoscopy for Establishing Individuality. Indian J Dent Adv 3: 427-432.

7. Palatinas R, de su Forma SdA (2009) Palatal rugae: Systematic analysis of its shape and dimensions for use in human identification. Int $\mathrm{J}$ Morphol 27: 819-825.

8. Gondivkar SM, Patel S, Gadbail AR, Gaikwad RN, Chole R, et al. (2011) Morphological study of the palatal rugae in western Indian population. J Forensic Leg Med 18: 310-312.

9. Shanmugam S, Anuthama K, Shaikh H, Murali K, Suresan V, et al. (2012) Palatal rugae in population differentiation between South and North Indians: A discriminant function analysis. J Forensic Dent Sci 4: 75-79.

10. Caldas IM, Magalhães T, Afonso A (2007) Establishing identity using cheiloscopy and palatoscopy. Forensic Sci Int 165: 1-9.

11. Yadav G, Singh S (2011) Forensic Odontology: Records, Implications and Limitations. J Indo-Pac Acad Forensic Odont 2: 18-21.

12. Jawad IA (2010) Comparison of rugae pattern between dentate and edentulous patients in Iraqi sample. Al-Rafidain Dent J 10: 265-271.

13. Fenn HRB, Liddelow KP, Gimson AP (1953) Clinical dental prosthetics (2ndedn), London, England: Staples Press.

14. Kapali S, Townsend G, Richards L, Parish T (1997) Palatal rugae patterns in Australian aborigines and Caucasians. Aust Dent J 42: 129-133.

15. Shukla D, Chowdhry A, Bablani D, Jain P, Thapar R (2011) Establishing the reliability of palatal rugae pattern in individual identification (following orthodontic treatment). J Forensic Odonto-Stomatol 29: 20-29.

16. Rajan VP, John JB, Stalin A, Priya G, Abuthagir AK (2013) Morphology of palatal rugae patterns among 5-15 years old children. J Pharm Bioallied Sci 5: S43-47.

17. Thomas CJ, Kotze TJ (1983) The palatal ruga pattern: a new classification. $J$ Dent Assoc S Afr 38: 153-157.

18. Cole SA (2001) Suspect Identities: A history of fingerprinting and criminal identification United States of America: Harvard University Press.

19. Sharma P, Saxena S, Rathod V (2009) Comparative reliability of cheiloscopy and palatoscopy in human identification. Indian J Dent Res 20: 453-457.

20. Paliwal A, Wanjari S, Parwani R (2010) Palatal rugoscopy: Establishing identity. J Forensic Dent Sci 2: 27-31.

21. Ohtani M, Nishida N, Chiba T, Fukuda M, Miyamoto Y, et al. (2008) Indication and limitations of using palatal rugae for personal identification in edentulous cases. Forensic Sci Int 176: 178-182. 